\title{
Lost in another language: a case report
}

\author{
Husam K. Z. Salamah ${ }^{1,2^{*}}$, Eva Mortier ${ }^{1}$, Renske Wassenberg ${ }^{1}$ and Jacqueline J. M. H. Strik ${ }^{1,2}$
}

\begin{abstract}
Background: In foreign language syndrome, patients switch from their native language and fixate for a period of time on a second language. There have been few reported cases. The language switch typically occurs postoperatively and spontaneously resolves after a short period of time. The primary cause of this switching remains unclear. There is speculation about the involvement of anesthesia, but its specific influence remains unclear.

Case presentation: A 17-year-old Dutch Caucasian male lost the ability to understand and speak Dutch for 24 hours after an orthopedic surgery, combined with a brief confused state including disorientation of place and the inability to recognize his parents. During the period, he communicated in English, which he had learned during school classes but had never spoken outside of school. Further follow-up, including neuropsychological examination, revealed no indication of cognitive impairment.

Conclusions: The exact pathophysiology of foreign language syndrome remains unclear, most specifically whether it is a syndrome of its own or a phenotype of emergence delirium. There is still much to be learned, and further research is needed.
\end{abstract}

Keywords: Language switch, Foreign language syndrome, Anesthesia, Emergence delirium, Postoperative, Nonnative, Case report

\section{Background}

Language switch after an operation or exposure to anesthetic is an exceptional presentation, and there is ambiguity surrounding the presentation and the exact cause. In the literature, some articles associate the language switch with "foreign language syndrome" (FLS), also known as "transient post-anesthetic foreign language fixation" and formerly known as "non-native language syndrome" In FLS, patients switch from their native language and fixate on a second language for a period of time.

To date, there has been no broader analysis of possible mental disturbances with which FLS could be associated. With this paper, we report a case of postoperative language switch (FLS) in a 17-year-old. In addition, we conducted a literature search to find similar cases of language

\footnotetext{
*Correspondence: husam.salamah@mumc.nl

${ }^{1}$ Department of Psychiatry and Department of Psychology, Maastricht

University Medical Center+, P.O. Box 5800, 6202 AZ Maastricht, the Netherlands

Full list of author information is available at the end of the article
}

switch. We use this opportunity to share our hypothesis of the clinical position of FLS within the concept of emergence delirium (ED), citing the close similarities in their respective onsets (for example, postoperatively, with possible association to anesthesia), presentations (for example, confusion state), and prognosis (recovery within hours).

\section{Case presentation}

A 17-year-old Dutch Caucasian male was admitted to the hospital following knee surgery for chondral defect of the lateral femoral condyle, after an incident during a game of football. He had no psychiatric or somatic comorbidities, other than factor $\mathrm{V}$ Leiden (which was under control), and this was his first time undergoing surgery and anesthesia. His past medical history included greenstick fracture of the distal radius in 2018, a fracture of the basis of the proximal phalanx fifth digit of the right hand in 2014, pneumonia in 2014, and fluctuating idiopathic dysphagia (since grade 3 ). The patient had no psychiatric original author(s) and the source, provide a link to the Creative Commons licence, and indicate if changes were made. The images or other third party material in this article are included in the article's Creative Commons licence, unless indicated otherwise in a credit line to the material. If material is not included in the article's Creative Commons licence and your intended use is not permitted by statutory regulation or exceeds the permitted use, you will need to obtain permission directly from the copyright holder. To view a copy of this licence, visit http://creativecommons.org/licenses/by/4.0/. The Creative Commons Public Domain Dedication waiver (http://creativeco mmons.org/publicdomain/zero/1.0/) applies to the data made available in this article, unless otherwise stated in a credit line to the data. 
history and no relevant medical family history. There was no notable family health history apart from depression on the mother's side of the family (great grandmother and grandfather). However, he had a psychiatric family history (great grandmother and a grandfather from his mother's side known with depression). At that time, he was still living at home with his biological parents and he had an older sister (19 years old). He had no relationship. Regarding his education, he was in his final year of high school, with a profile of nature and health.

The patient's native language was Dutch, and his second language was English. The latter was acquired in a nonbilingual school during regular English classes. He had only spoken English during these classes. He had spoken Dutch exclusively throughout his life, including on the morning of his surgery, and he spoke with a particular southern Dutch dialect (Limburgish). He had no relatives in any English-speaking country, and he had not recently visited any such country. Anesthesia was induced with various medications (Table 1). Upon emergence, the patient was confused and was taken to the recovery room, where a nurse noticed that he was speaking English. He said repeatedly that he was in the United States of America (specifically Utah), despite never having been to the USA. He did not recognize his parents and could neither speak nor understand Dutch. At that time, the nurse had no concerns and thought that the patient was unable to speak Dutch owing to a possible emergence delirium (ED) he was experiencing after the operation. However, a few hours after the surgery, all efforts to elicit a single Dutch word from him had been unsuccessful and psychiatric consultation was sought.

During the mental status examination, which took place approximately 18 hours after surgery, we found a relaxed, 17-year-old, well-groomed boy lying on the bed. We shook hands upon greeting. He made adequate eye contact and was open to communication. His attention could be attracted, and it was maintained well. During the interview, he was able to answer questions, but only in English, spoken with a Dutch accent. He gave only short answers in Dutch and did so with difficulty. His concentration seemed undisturbed. No thought delusions or hallucinations were observed during the conversation. His intelligence was estimated to be average. His mood was cheerful, with a normal affect. His use of the English language seemed adequate; his pronunciation and articulation were clear, with good intonation. His thinking, in terms of form and content, seemed undisturbed. He had a normal facial expression.

Approximately 18 hours postoperatively, the patient was able to understand Dutch but still could not speak it. The physicians involved observed that he spoke English adequately but appeared not to be fluent, while the nurses and his mother observed that he had the ability to speak the language fluently. Approximately 24 hours postoperatively, when some of his friends came to visit, he was able to spontaneously understand and speak Dutch again. Interestingly, during the mental status examination the next day, the boy revealed that he was aware he had been speaking and only able to understand English in the immediate postoperative period. In addition, he remembered that he had been unable to recognize his parents and that he had believed he was in the USA. The neurologist reported no abnormalities in the complete neurological examination. The neurologist saw no indication for further diagnostics; therefore, no electroencephalogram (EEG), neuroimaging, or neuropsychological examinations were performed near the event, and the patient was discharged a day later. Three weeks after discharge from the hospital in a follow-up appointment at the psychiatric outpatient clinic, he reported that he was experiencing no difficulties using the Dutch language. Furthermore, he experienced no other neurological complaints (for example, complaints regarding his senses). There were no changes in his mood and no presentation of anxiety, and his sleep was intact. He did report a decrease in his concentration (including difficulties storing information) or fatigue, especially after the operation. At three follow-up appointments ( 2 months, 5 months, and 10 months after discharge), these symptoms were gradually improving and there were no new symptoms reported nor observed.

However, almost a year after surgery (when the patient was already 18 years old), a neuropsychological examination was performed due to subjective memory complaints, with the patient indicating that he could not remember things as well as he had done before the surgery. The results of this investigation showed that the patient had a high-performance motivation. His performance in the test was generally average to very good. The patient was able to remember meaningful material to an excellent level, using the Loci method. His memorization of short series of numbers and words was below average. This showed that the patient benefited from repetition. He performed well in terms of vocabulary and visual spatial awareness. The test did not reveal any indication of a cognitive impairment, and the subjective memory complaints may have been due to the patient being fixated on regular forgetfulness.

\section{Discussion and conclusion}

We conducted a literature search in an online electronic database (including PubMed and the reference lists of the found articles), using relevant terms ("foreign language syndrome," "FLS," "non-native language," "rare diseases," "postoperative anaesthesia," "general/adverse effects," "knee surgery," "drug effects," "factor V Leiden," "language 


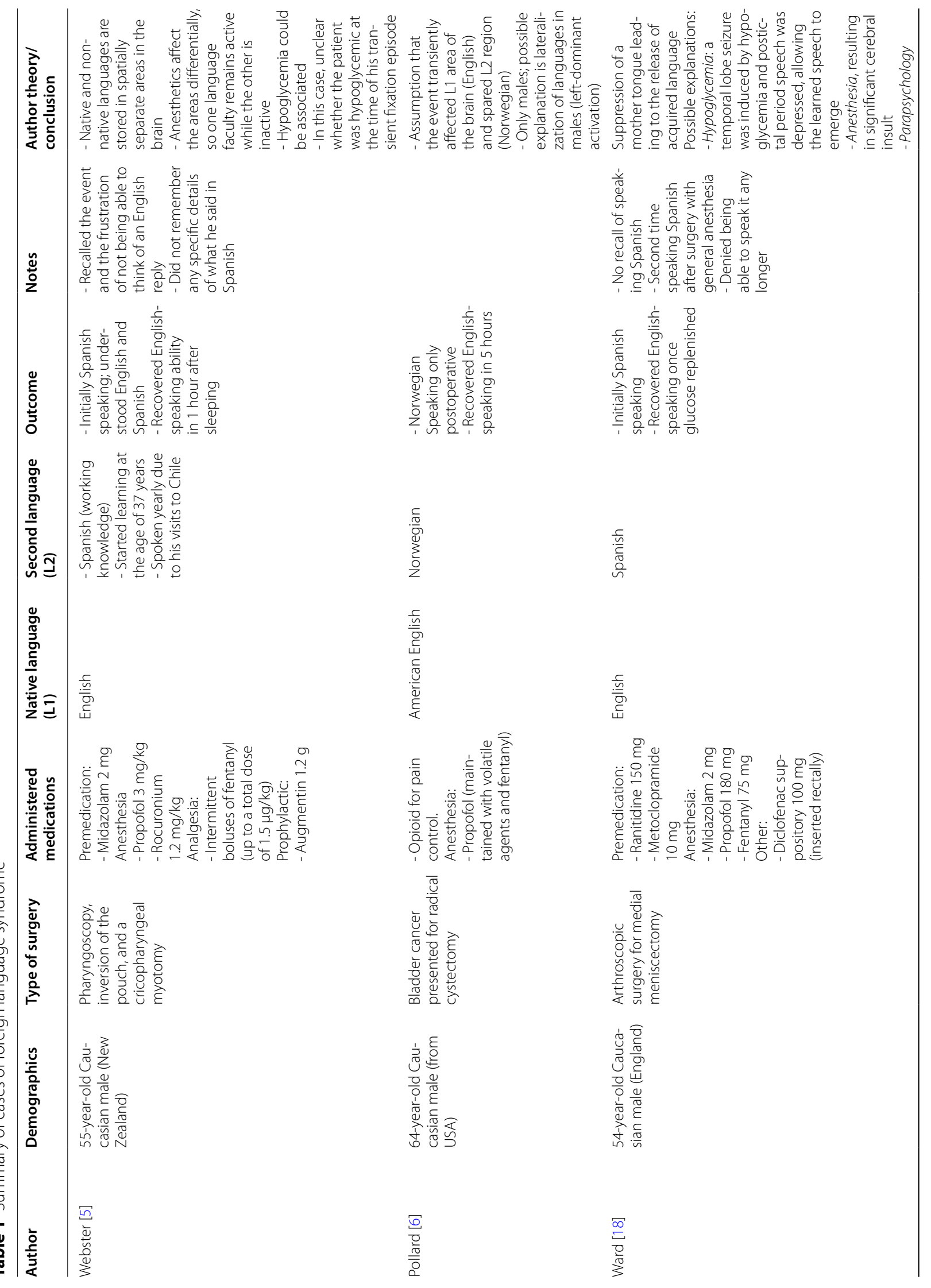




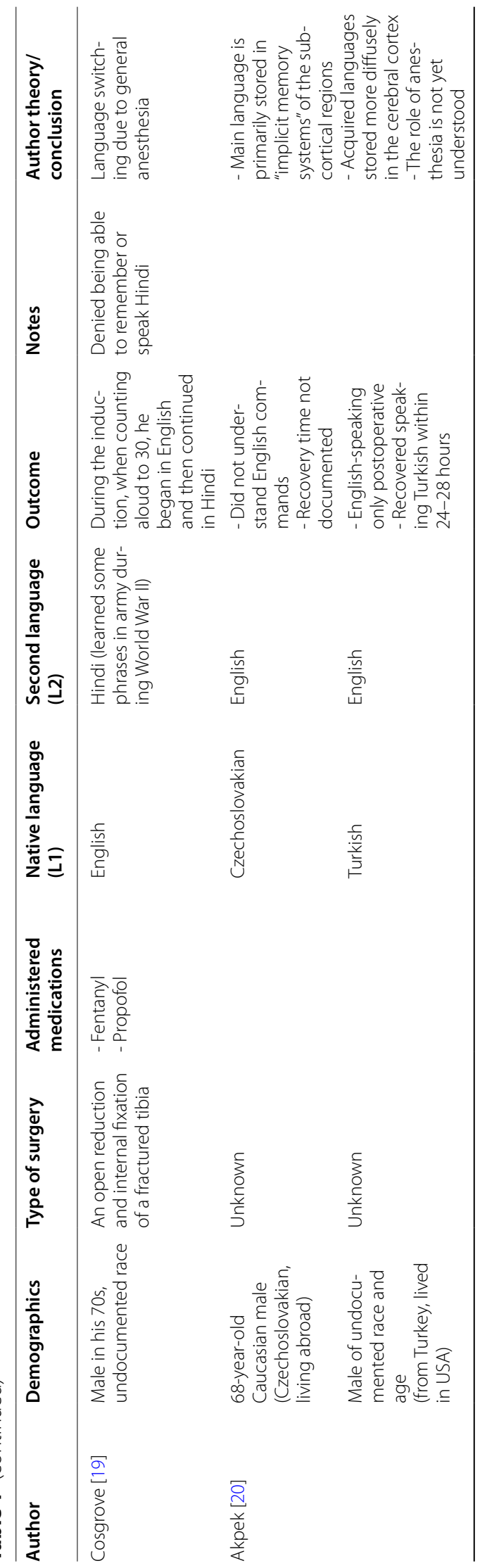




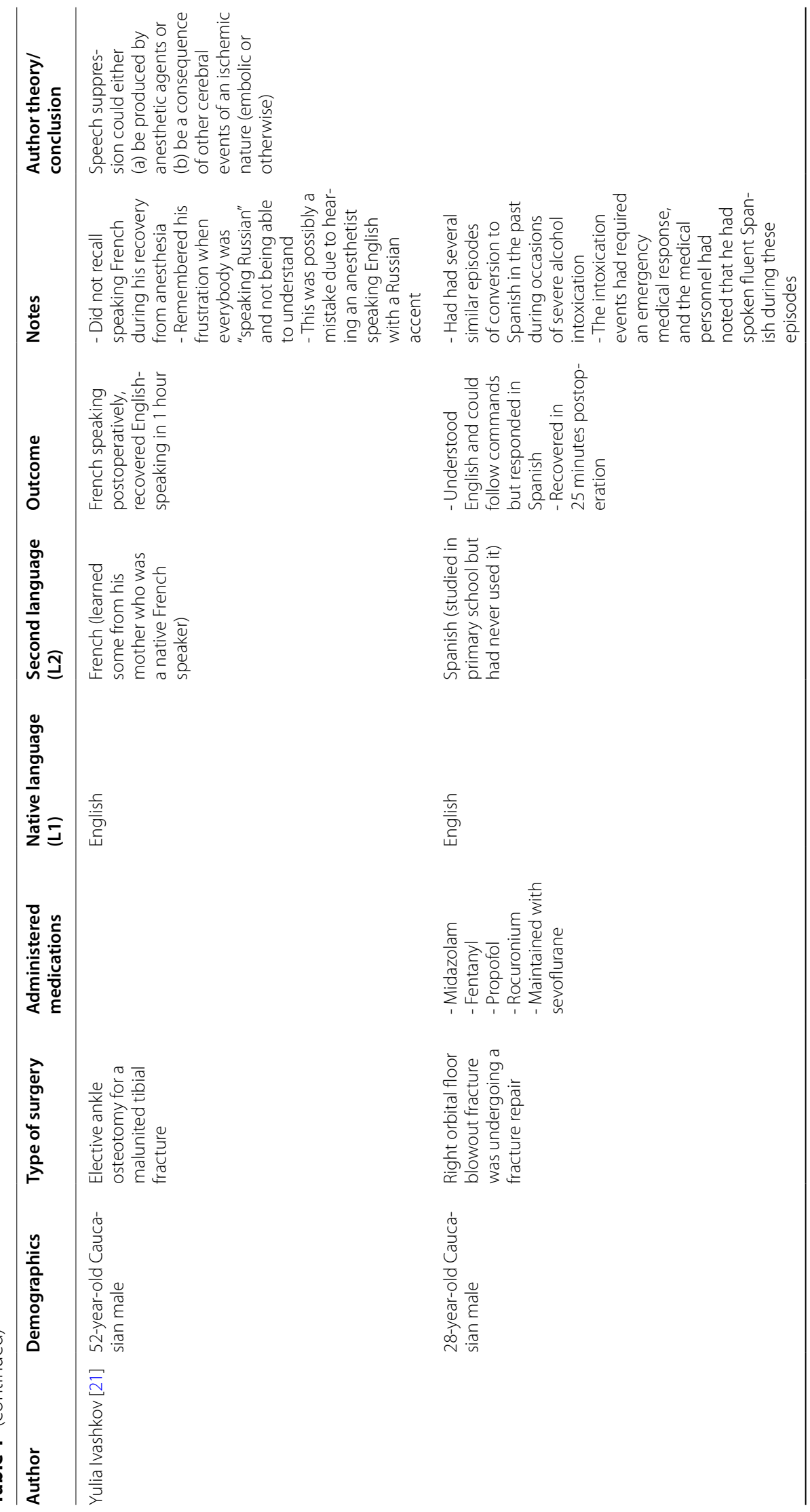




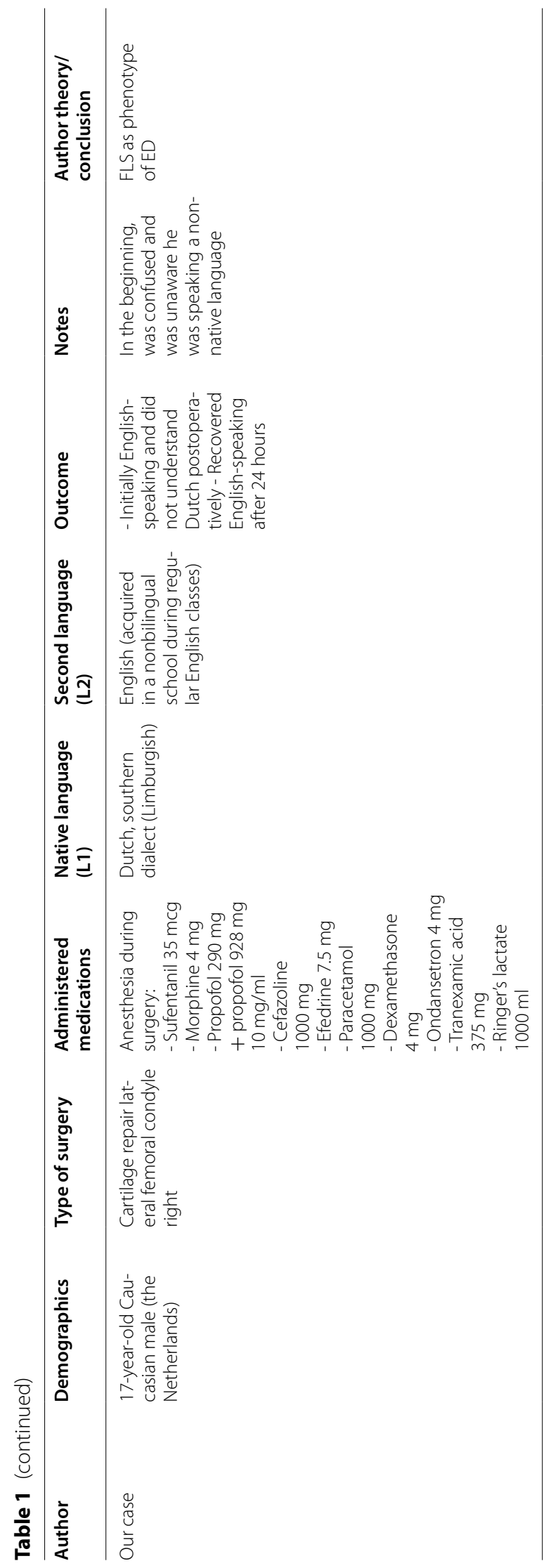


physiology," "Wernicke area/physiology," "Wernicke area/ drug effects," "monolingualism," and "multilingualism") and found eight relevant published cases of FLS. Table 1 summarizes these cases. Child cases of FLS are relatively rare. To the best of our knowledge, most of the reported child cases were presented in news outlets, rather than in scientific journals. Therefore, our case might be the first scientifically reported case of FLS in children/adolescents. Age was also a major difference between the found cases and our own, as all the former were adultsand six of the eight were above the age of 50 years (the age of one case was unknown, and another was 28 years old). Almost all cases-including our own-were male and Caucasian (in two cases, the race was unknown). In six of the cases, the native language was English. In five (including our own), the second language was reported to have been learned as a foreign language, as opposed to the patient being bilingual; the other four cases did not include this information. In five cases (including our own), the episodes occurred after an orthopedic surgery; and in all eight, they lasted between 25 minutes and 28 hours each. Four cases did not recall speaking the other language. Fentanyl, midazolam, and propofol were the most commonly reported anesthetics. No associations indicated whether FLS could be a phenotype of any other postoperative disorder or mental disturbance, such as emergence delirium (ED). As conversion disorder was included in our differential diagnosis (other differentials were ED and FLS), we conducted a brief general search and found three reports of foreign accent syndrome (FAS) being linked to conversion disorder-one of which was written in Japanese, though the abstract was in English [1-3]. FLS should not be confused with FAS, which is "a rare speech disorder consisting of speech rhythm changes perceived by listeners as a foreign accent, and different accents have been reported" [4 p. 1123]. FLS may be similar in presentation, but the onset and clinical course of our clinical case dispute this. In our case, there was no speech production problem, but rather a complete switch of a spoken language and an inability to speak one's own language.

Although we found only eight relevant cases with a variety of hypotheses and assumptions, it should be noted that the use of non-native languages might go unrecognized by clinical staff who are not familiar with them. The question also arises as to whether our patient was able to speak English fluently. In one case presented by Webster et al. the nurse (a Spanish-speaking nurse) reported that the patient's speech was fragmented and he was repeating a specific single phrase several times [5]. The patient discussed by Pollard et al. was not able to speak Norwegian fluently, according to his spouse [6]. Although this was refuted by the anesthesiologist, he was actually from Croatia; thus, Norwegian was not his native language.

Another phenomenon that frequently occurs after operations and anesthetics that could, in our opinion, be related to FLS is ED. We hypothesize that FLS could be a phenotype of ED, rather than a problem of its own. Sikich et al. define ED as "a disturbance in a child's awareness or attention to his/her environment with disorientation and perceptual alterations including hypersensitivity to stimuli and hyperactive motor behaviour in the immediate post anaesthesia period" [7 p. 1139]. The specific mechanism of ED in children remains unknown. Pain and perioperative anxiety may be contributing factors in causing ED [8]. However, this was not applicable to our case. Therefore, we chose not to focus on this further. The possible involvement of anesthesia is another interesting hypothesis, as the incidence of ED is increasing since the introduction of fast-acting volatile agents (for example, sevoflurane and desflurane) [8]. The effect of anesthesia on cognition has been observed in animal studies. In those studies, apoptotic neurodegeneration and long-term cognitive deficiencies have been reported in immature animals exposed to anesthesia [9]. This might explain the experienced lack of concentration in our case.

Dahmani et al. reported different possible mechanisms of ED related to anesthesia [8];

Differential recovery rate of brain functions from anesthesia could be caused by the clearance of volatile agents from the central nervous system. It has been hypothesized that the late emergence of cognitive function is the cause of the confusion state in ED. It has also been demonstrated that propofol could be preventive against ED, compared with sevoflurane and desflurane.

The connectivity of brain areas would be susceptible of change while under anesthesia. It has been hypothesized that volatile (such as sevoflurane) and intravenous agents (such as propofol) have several effects on brain networks and might account for differences in recovery manifestations [8]. Based on the first hypothesis, our patient should have had less chance to develop ED, yet the second hypothesis does not exclude the effect of propofol in causing ED.

Some of the found cases report that their patient lacked self-awareness, denied being able to speak in the non-native language, and was unaware that they had spoken or written in a non-native language. These could be signs of confusion and disorientation, as seen in ED. Our patient was initially confused (unable to recognize his family, for example), disoriented in place, and unaware that he was speaking a non-native language. Later, he indicated that he was able to remember not speaking in his native tongue. However, it might be that he only believed he was able to remember because he had been 
told by clinical staff, family members, and friends what had happened. Language can be affected in delirious patients. Green et al. demonstrated that the production of spontaneous speech, word quantity, speech content, and verbal and written language comprehension are impaired in delirious patients compared with cognitively unimpaired patients [10]. Malarbi et al. report that irrelevant language, activity, and vocalization are behaviors associated with ED, demonstrating that anesthesia can result in ED and cause possible disturbance in language [11].

An argument may arise regarding recovery time, as the recovery time of FLS can be up to 28 hours, whereas symptoms of ED are thought to occur within 30 minutes of termination of anesthesia and last for 15-30 minutes. However, this is a very common misunderstanding regarding $\mathrm{ED}$, which has been reported to last up to 2 days. The recovery of our patient is thus within this margin.

The exact pathophysiology of FLS remains unclear. Most importantly, we do not know whether it is a syndrome on its own or a phenotype of another syndrome or disorder (for example, ED). This case report sheds light on the possible occurrence of this phenomenon in children not only in adults, as most of the reported cases on FLS. Furthermore, it raises awareness of the probable relations between FLS and ED, which gives the opportunity for better prevention and intervention. As we have demonstrated, ED arises from a combination of factors in which the strongest evidence has been found for undergoing anesthesia and choice of anesthetic. However, patient- and environment-related factors may also have a contributing role, although this is less strongly proven. Non-drug interventions such as preparation for surgery through a tour of the operating room and parental participation in the perioperative process can also play a role in the prevention of ED [12-17]. In addition to non-drug interventions, drug interventions deserve a role in the prevention of ED.

Clinical research on different phenotypes of delirium is important, especially postoperatively and in the emergency ward, to optimize patient care. Thus, there is still much to be learned, and further research is needed.

\section{Abbreviations \\ ED: Emergence delirium; FLS: Foreign language syndrome; FAS: Foreign accent} syndrome.

\section{Acknowledgements}

Clinical staff who contributed to the care of this patient.

\section{Authors' contributions}

HKZS and EM provided patient care and follow-up, collected patient data, and wrote and revised the manuscript. JJMHS and RW provided patient care and follow-up, and reviewed and revised the manuscript. All authors read and approved the final manuscript.

Funding

Not applicable.

Availability of data and materials

Data sharing is not applicable to this article, as no datasets were generated or analyzed during the current study.

\section{Declarations}

Ethical approval and consent to participate

In our institution, institutional review board approval is not required for a case report.

\section{Consent for publication}

Written informed consent was obtained from the patient for publication of this case report and any accompanying images. A copy of the written consent is available for review by the Editor-in-Chief of this journal.

\section{Competing interests}

The authors declare that they have no competing interests.

\section{Author details}

${ }^{1}$ Department of Psychiatry and Department of Psychology, Maastricht University Medical Center+, P.O. Box 5800, 6202 AZ Maastricht, the Netherlands $\swarrow$ ${ }^{2}$ School for Mental Health and Neuroscience (MHeNs), University of Maastricht, Maastricht, the Netherlands.

Received: 26 October 2021 Accepted: 20 December 2021

Published online: 22 January 2022

\section{References}

1. Tsuruga K, Kobayashi T, Hirai N, Kato S. Foreign accent syndrome in a case of dissociative (conversion) disorder. Seishin Shinkeigaku Zasshi. 2008;110:79-87 (Japanese).

2. Jones HN, Story TJ, Collins TA, DeJoy D, Edwards CL. Multidisciplinary assessment and diagnosis of conversion disorder in a patient with foreign accent syndrome. Behav Neurol. 2011:24:245-55.

3. Verhoeven J, Mariën P, Engelborghs S, D'Haenen H, De Deyn P. A foreign speech accent in a case of conversion disorder. Behav Neurol. 2005;16:225-32.

4. Chanson JB, Kremer S, Blanc F, Marescaux C, Namer IJ, de Seze J. Foreign accent syndrome as a first sign of multiple sclerosis. Mult Scler. 2009;15:1123-5.

5. Webster CS, Grieve ROS. Transient fixation on a non-native language associated with anaesthesia. Anaesthesia. 2005:60:283-6.

6. Pollard EM, Weingarten TN, Sprung J. Postoperative foreign language syndrome. J Clin Anesth. 2017;38:7-8.

7. Sikich N, Lerman J. Development and psychometric evaluation of the pediatric anesthesia emergence delirium scale. Anesthesiology. 2004:100:1138-45

8. Dahmani $\mathrm{S}$, Delivet H, Hilly J. Emergence delirium in children. Curr Opin Anaesthesiol. 2014:27(3):309-15.

9. Ing C, DiMaggio C, Whitehouse A, Hegarty M, Brady J, von UngernSternberg $\mathrm{B}$, et al. Long-term differences in language and cognitive function after childhood exposure to anesthesia. Pediatrics. 2012;130(3):476-85.

10. Green S, Reivonen S, Rutter LM, Nouzova E, Duncan N, Clarke C, et al. Investigating speech and language impairments in delirium: a preliminary case-control study. PLoS ONE. 2018. https://doi.org/10.1371/journal. pone.0207527.

11. Malarbi S, Stargatt R, Howard K, Davidson A. Characterizing the behavior of children emerging with delirium from general anesthesia. Pediatr Anaesth. 2011:21:942-50

12. Eijlers R, Dierckx B, Staals LM, Berghmans JM, van der Schroeff MP, Strabbing EM, Wijnen RMH, Hillegers MHJ, Legerstee JS, Utens EMWJ. Virtual 
reality exposure before elective day care surgery to reduce anxiety and pain in children. Eur J Anaesthesiol. 2019;36:728-37.

13. Hilly J, Hörlin AL, Kinderf J, et al. Preoperative preparation workshop reduces postoperative maladaptive behavior in children. Paediatr Anaesth. 2015;25(10):990-8.

14. Ryu JH, Oh AY, Yoo HJ, Kim JH, Park JW, Han SH. The effect of an immersive virtual reality tour of the operating theater on emergence delirium in children undergoing general anesthesia: a randomized controlled trial. Paediatr Anaesth. 2019;29(1):98-105.

15. Zhong $\mathrm{Q}, \mathrm{Qu} X, \mathrm{Xu}$ C. Effect of preoperative visiting operation room on emergence agitation in preschool children under sevoflurane anesthesia. Int J Pediatr Otorhinolaryngol. 2018;104:32-5.

16. Arai YC, Ito H, Kandatsu N, Kurokawa S, Kinugasa S, Komatsu T. Parental presence during induction enhances the effect of oral midazolam on emergence behavior of children undergoing general anesthesia. Acta Anaesthesiol Scand. 2007;51(7):858-61.

17. Kain ZN, Caldwell-Andrews AA, Mayes LC, Weinberg ME, Wang SM, MacLaren JE, Blount RL. Family-centered preparation for surgery improves perioperative outcomes in children: a randomized controlled trial. Anesthesiology. 2007;106(1):65-74.

18. Ward ME, Marshall JC. 'Speaking in tongues': paradoxical fixation on a non-native language following anaesthesia. Anaesthesia. 1999;54:1201-3.

19. Cosgrove JF.' 'Speaking in tongues.' Fixation on a non-native language at induction of anaesthesia. Anaesthesia. 2000;55:728.

20. Akpek EA, Sulemanji DS, Arslan G. Effects of anesthesia on linguistic skills: can anesthesia cause language switches? Anesth Analg. 2002;95(4):1127.

21. Ivashkov Y, Hui C, Bhananker SM. Transient post-anaesthetic foreign language fixation: two case reports. Anaesth Cases. 2016;4:53-7.

\section{Publisher's Note}

Springer Nature remains neutral with regard to jurisdictional claims in published maps and institutional affiliations.

- fast, convenient online submission

- thorough peer review by experienced researchers in your field

- rapid publication on acceptance

- support for research data, including large and complex data types

- gold Open Access which fosters wider collaboration and increased citations

- maximum visibility for your research: over $100 \mathrm{M}$ website views per year

At BMC, research is always in progress.

Learn more biomedcentral.com/submissions 